\title{
0 teatro para crianças nas vésperas da Revolução
}

\author{
Glória Bastos
}

\begin{abstract}
Os anos imediatamente anteriores à instauração da democracia em Portugal, em Abril de 1974, dão início a uma dinâmica de mudança na área do teatro para crianças, que será depois ampliada pelas condições mais favoráveis que o novo contexto político, social e cultural viria propiciar. Tratando-se de um campo ao qual, em geral, se tem prestado menos atenção no que aos estudos teatrais diz respeito, é também por isso um campo particularmente fecundo pelas facetas que nos podem ser dadas a descobrir. A nossa intenção é, pois, apresentar alguns apontamentos referentes ao período mencionado - intento que não deixa de apresentar algumas dificuldades, face ao "silêncio" atrás referido, que tem marcado de forma sistemática a produção teatral para crianças e jovens. Tentaremos caracterizar com brevidade 0 trabalho então desenvolvido e perspectivar como nesse momento são vividas algumas das tensões que marcam a criação teatral para os mais novos (tanto ao nivel da escrita como na vertente espectacular).
\end{abstract}

Em termos de publicação de textos dramáticos, os cinco anos anteriores a 1974 não são fartos na oferta editorial. Continuamos a encontrar propostas que prolongam uma das mais fortes linhas que caracterizam a publicação de textos nesta área: o teatro escolar representado por crianças. Com esta perspectiva, encontramos: Teatrito da escola (1971), de Fernando Ferreira; Recreio teatral (1971 Papelaria Fernandes), de Reinaldo Ferreira; e Teatro paro gente miúda (1970), o volume publicado pela Mocidade Portuguesa, que reúne textos de Maria Margarida Saraiva Carrinho, Ester de Lemos e Maria Teresa Andrade Santos, já antes representados no âmbito das actividades da MP.

Também na senda da recuperação de anteriores textos, Alice Gomes publica, em edição de autor, em 1972, A lenda das amendoeiras em flor e A nau Catrineta, dois textos jà incluidos no volume Teatro para crianças (1967), tendo a última peça aqui referida sido representada no início

Glória Bastos é Professora Auxiliar na Universidade Aberta.

Tem trabalhado, sobretudo, nas áreas da literatura para crianças jovens e da promoção da leitura e bibliotecas escolares. Publicou $O$ teatro para crianças em Portugal: História

e critica (2006). dos anos cinquenta, no Teatro Nacional, pela Companhia de Amélia Rey Colaço-Robles Monteiro. De Alice Gomes é ainda editado, em 1973, Os ratos e o trovador. Este conjunto de textos são igualmente representativos do que reconhecemos constituir uma das dominantes de escrita mais forte no teatro para crianças, que se consubstancia na reescrita e adaptação de textos da tradição. Outra das vertentes mais significativas desse teatro é a presença de personagens animais, que Fernando Melro expõe em Auto

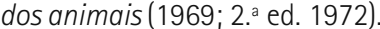

Maria Isabel de Mendonça Soares destaca-se durante os anos setenta, sendo a sua obra um bom exemplo de uma forte preocupação com a dimensão lúdica da língua aspecto fulcral quando nos referimos à escrita dramática dirigida ao jovem espectador. Os seus textos - Quem conto um conto... (1970, MPF), Os tamanquinhos de pau (1973, Logos), Al-godão e Al-godinho (1973) e Uma gralha entre pavões (1973) - apresentam uma escrita que revela uma atenção particular ao ritmo, pelo recurso frequente a uma prosa rimada. São pequenos textos dramáticos que colocam em confronto personagens cuja acção vai destacar a importância da entreajuda que, em alguns casos, incluem sugestões para a sua encenação, perspectivando um possivel trabalho em ambiente escolar.

Mas os textos que mais sobressaem no período aqui considerado, pela sua qualidade e pela renovação de algumas perspectivas, sobretudo na abordagem temática, são da autoria de Norberto Ávila, Ilse Losa e Isabel da Nóbrega.

Em As histórias de Hakim (1968, Edições Panorama) e A ilha do Rei Sono (representado em França, em 1965 segundo o autor, mas só publicado em 1977), Norberto Ávila denota um certo sabor de sátira social, estabelecendo, por exemplo, em alguns momentos, um curioso contraponto entre o universo da realidade, do quotidiano e os domínios do imaginário e do sonho. Também em termos estruturais, as duas peças se aproximam, uma vez que ambas apresentam narrativas de encaixe, fundandose em personagens que revelam uma significativa capacidade de "contadores", convidando, com as suas histórias, a uma reflexão e a um questionamento sobre o mundo.

Se os textos de Norberto Ávila apresentam uma qualidade literária superior, talvez que a peça mais inovadora em termos de uma proposta de leitura plural do mundo, posicionando-se num pólo de maior abertura à capacidade interrogativa e interpretativa do leitor/espectador perante o texto e o real, seja a composição de Isabel da Nóbrega, A cigarra e as formigas (1971, Movimento). Partindo, como o título claramente indica, da conhecida fábula, a peça vai desenvolver depois uma nova proposta de leitura, com a valorização das capacidades musicais da cigarra. Começa, no entanto, por elaborar um curioso processo de mise en abîme, ao estabelecer dois niveis de representação, com duas meninas que introduzem observam e comentam a apresentação do argumento da fábula.

No diálogo que encetam, discutem as relações e as influências que podem existir entre o dentro e o fora da história central, já conhecida pelos potenciais 


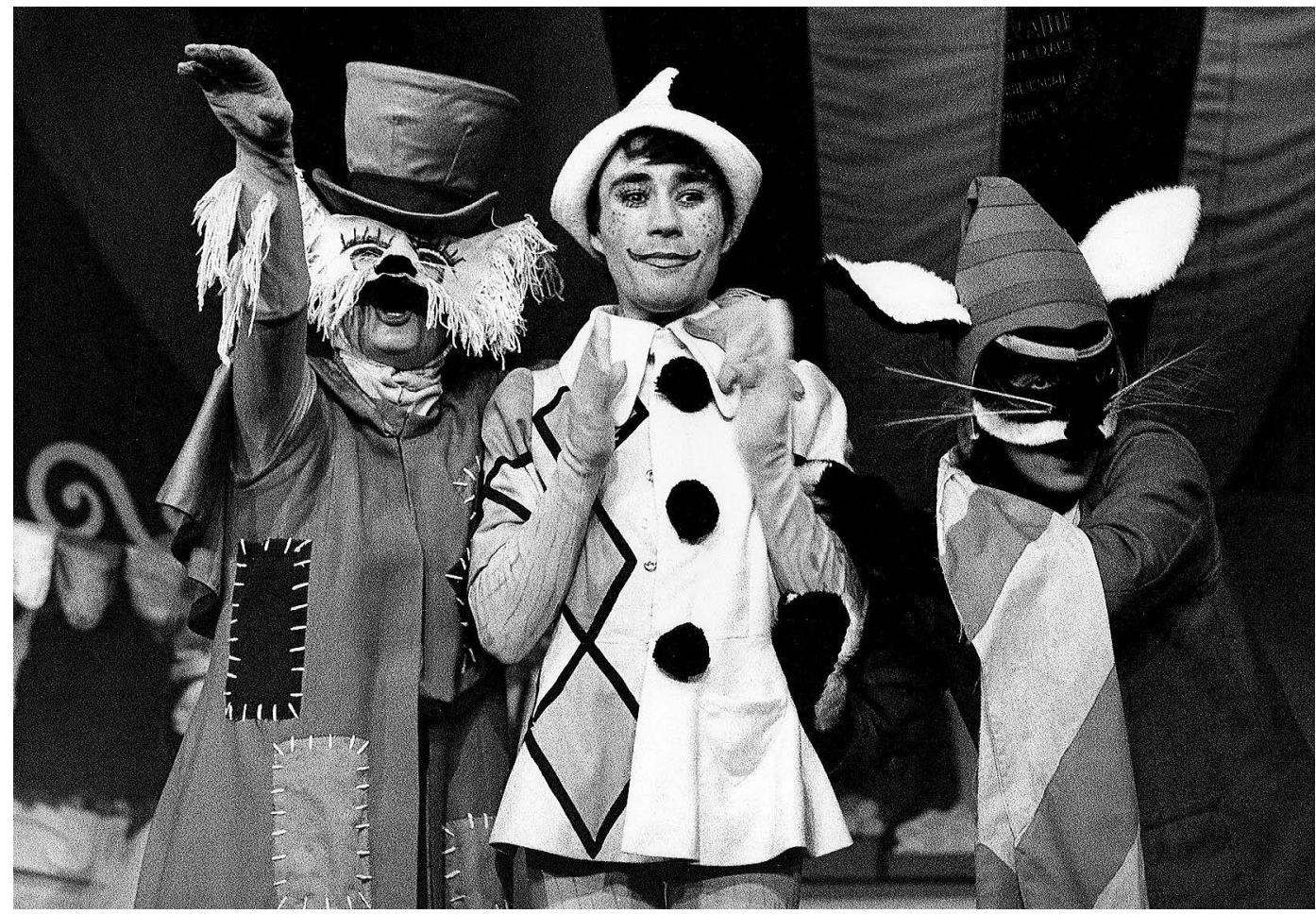

Pinóquio,

de Carlo Collodi,

enc. António de Cabo

e Pinto de Campos, Teatro Monumental, 1972

[cortesiado Museu Nacional do Teatro].

leitores/espectadores. Há, pois, um convite a uma atitude de abertura e de questionamento perante as relações entre a literatura e o mundo, que vai encontrar eco noutra personagem igualmente conotada com um certo inconformismo perante as "leituras" fechadas do mundo: trata-se da segunda Formiga, que propõe também uma nova "leitura"/representação da fábula, e que comentará: "Gosto de perceber tudo, gosto de saber o que é que as coisas são por dentro, para perceber como é que elas são por fora". Este entendimento conduz, nomeadamente, à indução de uma atitude idêntica, por parte dos

destinatários, de questionamento daquilo que é observado e não de aceitação passiva dos factos, com críticas veladas aos horizontes limitados que o regime sempre pretendeu impor: "Ter asas para voar! Afinal, cantar é uma espécie de voar, não é? Eu nasci prudente, económica e arrumada, mas sou triste... Nunca ouço música dentro de mim, nem sei cantar..." (Ibidem: 18).

Esta recusa em aceitar um futuro pré-estabelecido encontra-se igualmente na peça de Ilse Losa, 0 príncipe nabo da nabolândia, publicada em conjunto com João e Guida (1962, Divulgação). Enquanto no primeiro texto vemos a protagonista recusar os papéis que tradicionalmente lhe estão atribuidos nas histórias de princesas, o segundo texto parte, como muitos outros, de uma história da tradição, para em seguida reelaborar os eixos temáticos da matriz e inserir elementos que questionam essa mesma matriz. Neste caso concreto, tal ocorre através da introdução de preocupações de cariz social e ética que projectam a história narrada no presente histórico do momento da leitura ou da representação.

Recuamos aqui alguns anos em relação ao periodo considerado inicialmente, por João e Guida ser um dos poucos textos publicados em livro, por autores portugueses, que foram levados à cena - neste caso, pelo grupo teatral LATA (Laboratório Amador de Teatro Actual) do Porto (em Dezembro de 1973). Também a peça de Isabel da Nóbrega conhece essa fortuna, tendo sido apresentada pela Casa da Comédia (em Dezembro de 1971), com larga participação das escolas. Nestes dois casos, deve-se justamente salientar a escolha de textos que, como se referiu antes, estabelecem uma certa disjunção temática relativamente a outros publicados na mesma altura (anos sessenta e setenta), implicando uma opção consciente por abordagens em que a reflexão de cariz social está patente, pois é um traço importante nessas peças, quando sabemos que tal tipo de considerações estava ausente na maior parte dos livros escritos para os mais novos.

Mas, de facto, a maioria dos espectáculos então apresentados (à semelhança, aliás, do que continua a acontecer hoje) assentava, primeiro, na adaptação dramática de textos tradicionais ou de clássicos infantis $\mathrm{e}$, segundo, no recurso, mais frequente durante este período, a autores estrangeiros conceituados na área do teatro infantil. Vejamos alguns exemplos destas duas orientações.

Em 1970, temos O Natal do Capuchinho Vermelho, no Teatro Monumental. Durante o ano de 1971, a companhia do Capitólio apresenta Branca de Neve; enquanto o Teatro Variedades propõe um "Carnaval infantil" com as peças A bruxinha que era boa e A Gata Borralheira, de Maria Clara Machado e, na Páscoa seguinte, Era uma vez uma Carochinha. Ainda ao longo do ano de 1972, o Teatro Tico-Tico, apoiado pela autarquia lisboeta, propõe Um senhor gato de botas altas, que é apresentado em algumas salas de teatro e nas escolas da cidade; e o Teatro do Gerifalto surge com A lela e o monstro.

Dois conhecidos clássicos da literatura infantil são também encenados neste periodo. No início de 1971, o TEJE (Teatro do Jovem Espectador) apresenta Emilio e os detectives, no Teatro Villaret, com encenação de Glicínia Quartin. Sobre a peça escreveu na altura Alice Ogando, destacando o seu bom acolhimento pelos jovens espectadores, sobretudo para quem "não [lhes] baste o 


\section{Pinóquio, \\ de Carlo Collodi, \\ enc. António de Cabo \\ e Pinto de Campos, \\ Teatro Monumental, 1972}

[cortesia do Museu

Nacional do Teatro].
A Bela e o Monstro, Teatro do Gerifalto, Teatro Éden, 1972 [cortesiado Museu Nacional do Teatro].
'Capuchinho'" (Plateia, 19 de Janeiro de 1971), numa alusão explícita a uma certa dominação do palco pela literatura tradicional. Em 1972, a peça Pinóquio é apresentada no Teatro Monumental, sob responsabilidade do empresário Vasco Morgado, cujo empenho em produzir um espectáculo com qualidade é saudado pela imprensa, apesar de alguns aspectos considerados menos bem conseguidos.

No que se refere às companhias empenhadas num trabalho mais continuado nessa área, verificamos que as opções se centram sobretudo no recurso a autores e textos de prestígio reconhecido. É o caso de Maria Clara Machado, a cujas peças se recorre largamente nestes três/quatro anos, com uma diferença significativa sobre a sua escrita (a maioria fora publicada no volume Teatro infantil, em 1959), como se reconhece na altura: "isto [a apresentação das peças no Brasil] começou há vinte anos... o tempo aproximado que levaram a atravessar o Atlântico as suas mensagens teatrais, simples e construídas com amor tocante pelo mundo infantil" (Plateia, 4 de Maio de 1971). Deixamos aqui apenas alguns registos da adesão então manifestada pelos grupos aos textos da dramaturga brasileira: para além das adaptações já mencionadas acima, em 1971, a Casa da Comédia encena O rapto das cebolinhas, o Teatro do Arco da Velha apresenta, durante o ano de 1972. A menina e o vento, 0 cavalinho azul e A bruxinha que era boa e, em 1973 e 1974, O fantasminha Pluft, peça que também é oferecida por Vasco Morgado, no Teatro Laura Alves, numa encenação de Jacinto Ramos (em Dezembro de 1972).

Em relação à vertente espectacular do teatro infantil, de que temos vindo a falar, uma preocupação sobre a qualidade dos trabalhos que são apresentados cruza vários dos comentários que vão surgindo na imprensa. Estabelecese, nomeadamente, um contraponto entre um desejável "novo estilo" de teatro infantil e a manutenção dos "velhos mitos" (leia-se, histórias tradicionais) que os adultos têm para oferecer às crianças ou uma apresentação "convencional e ar muito professoral" (notas sobre a peça Pinóquio, Diário popular, 14 de Fevereiro de 1972).

Esse estilo novo surge sobretudo associado a duas Companhias que aparecem durante o período aqui considerado. Em primeiro lugar, Os Bonecreiros e a sua tentativa de "teatro independente", iniciada com a peça O circo imaginário do Super Basílio (1971). Com encenação de João Mota, esta peça vai ganhar o prémio da crítica para melhor espectáculo para a infância e juventude desse ano, sendo apontada na imprensa como um espectáculo "diferente do que se tem até aqui experimentado para modificar os processos e renovar a cena" (Diário popular.
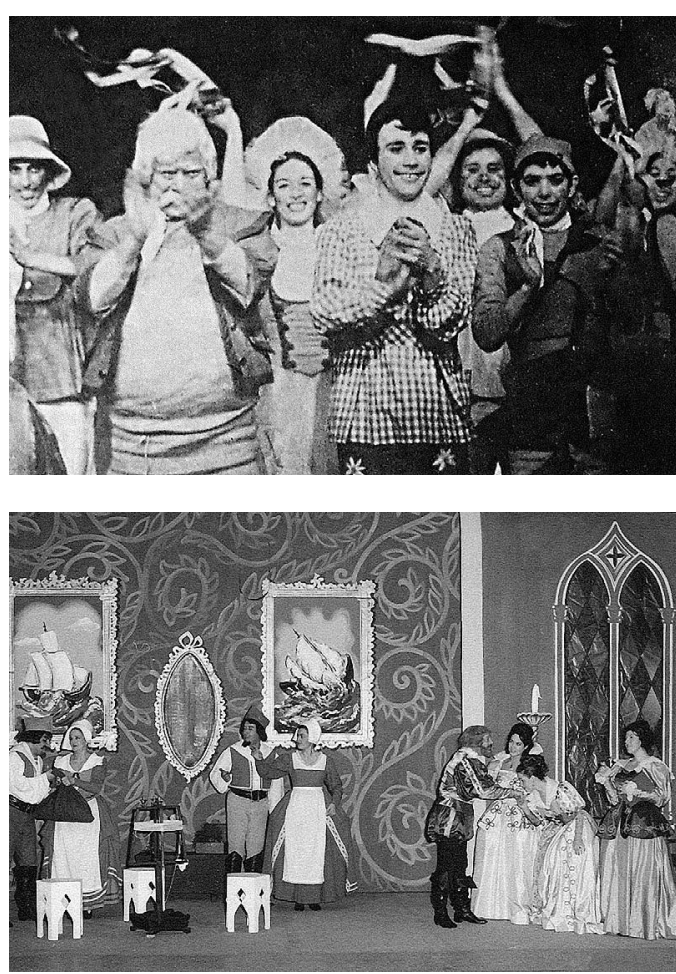

10 de Dezembro de 1971). Logo em 1972, uma parte do grupo abandona o colectivo para constituir uma nova Companhia, a Comuna Teatro de Pesquisa, e que inclui também nas suas primeiras aparições em público espectáculos para os mais novos: Feliciano e as batatas, de Catherine Dasté (1972) - que conquista o Prémio de Teatro da Casa da Imprensa - e, em 1973, a criação colectiva, Vamos para Maljupiki.

No campo do teatro amador, uma referência também para a intervenção do TEUC (Teatro dos Estudantes da Universidade de Coimbra) neste campo de expressão, com O palhaço troca o passo, de Manuel Guerra (1971), e Jerónimo, a tartaruga e o eucalipto feiticeiro, de Catherine Dasté (1973). Em entrevista dada, em 1973, ao jornal Notícias da Amadora (de 2 de Junho), a companhia afirmava a sua intenção formativa: "O TEUC realiza anualmente dezenas de espectáculos de teatro infantil que exigimos que sejam gratuitos. Efectivamente o TEUC a partir de 1969 tem levado o seu teatro infantil a aldeias, vilas, escolas primárias, escolas do ciclo preparatório, etc. contribuindo para a divulgação deste teatro que pretende incutir nas crianças desde cedo o seu gosto pelo teatro" - no artigo original foi censurada parte da entrevista em que se faz referência às tentativas de silenciamento do teatro universitário.

0 breve percurso aqui esboçado, necessariamente incompleto, procura ilustrar os movimentos divergentes que se vão construindo, em relação ao teatro para crianças e jovens, nos anos que antecedem o fim da ditadura.

Temos, por um lado, um trabalho apoiado num reportório de cariz mais tradicional, assente sobretudo no recurso a adaptações de contos populares e de histórias para crianças e jovens e, por outro, uma via de inovação e de alguma experimentação que surge representada por grupos que procuravam então assumir uma posição de ruptura com um certo status quo instalado e que, curiosamente, iniciam a sua actividade com propostas na área infantil. 